\title{
Patient experience - the ingredient missing from cost-effectiveness calculations
}

This article was published in the following Dove Press journal:

Patient Preference and Adherence

28 May 20II

Number of times this article has been viewed

\section{David Curtis}

Centre for Psychiatry, Barts and the London School of Medicine and Dentistry, London, UK
Correspondence: David Curtis Adult Psychiatry, Royal London Hospital, London EI IBB, UK

Tel +44207377 7729

Fax +44 2073777316

Email davidcurtis@nhs.net
Abstract: Standard cost-effectiveness calculations as used by the UK National Institute of Clinical Excellence compare the net benefit of an intervention with the financial costs to the health service. Debates about public health interventions also focus on these factors. The subjective experience of the patient, including financial costs and also transient pain, distress, and indignity, is routinely ignored. I carried out an Internet survey which showed that members of the public assign a high financial cost to routine medical interventions such as taking a tablet regularly or attending a clinic for an injection. It is wrong to ignore such costs when attempting to obtain an overall evaluation of the benefit of medical interventions.

Keywords: screening, prevention, financial cost, medical interventions

In a recent heated debate about the pros and cons of mammography, combatants on both sides brought to the argument disputed numbers regarding deaths prevented against harm caused by overdiagnosis and needless treatment. ${ }^{1-3}$ The guidelines produced by the UK National Institute of Clinical Excellence (NICE) on assessing cost-effectiveness of an intervention instruct that the costs of treatment options should be considered relative to their health benefits. ${ }^{4}$ In order to evaluate whether it is worth treating a section of the population with antiplatelet agents one would expect to take account of the health benefits from preventing thrombotic events weighed against additional morbidity and mortality from bleeding and the cost to the UK National Health Service (NHS) of delivering the treatment. ${ }^{5}$ What is missing from all these scenarios is any consideration of the cost to the individual patient of the intervention. These costs are not trivial and it does not make sense to omit them when deciding whether or not to promote an intervention.

Typically, the NHS will go about offering an intervention to a patient in two stages. Firstly, a cost-effectiveness calculation will be carried out to see whether it is worthwhile in terms of the net benefit divided by the financial cost. If the intervention is seen as cost-effective then it will be promoted to the patient as being of net benefit. The patient will be encouraged to accept the intervention because it is "good for them" even if it may cause them some degree of pain, distress, indignity, or financial loss. From this account, it can be seen that the "net benefit" is in fact counted twice - once against the financial cost to the health service and once against any costs to the patient. A recent example of how this process was followed is provided by the introduction of human papilloma virus (HPV) vaccination for 13-year-old females in the UK. First, a cost-effectiveness study, which considered financial costs, clinical outcomes, 
and economic outcomes, was carried out. ${ }^{6}$ Subsequently, a vaccination program was introduced, and the patient information leaflet explains the clinical benefits and side effects (http://www.cks.nhs.uk/patient_information_leaflet/hpv_ vaccination). These side effects were not considered in the cost-effectiveness study.

Although a typical cost-effectiveness calculation will take account of major negative health outcomes for the patient, such as increased mortality, morbidity, or disability, a variety of other effects on the patient will be partially or completely ignored: time taken off work or away from childcare; transient pain, nausea, or distress; and indignity. ${ }^{6}$ In many scenarios these personal and financial costs, borne by the individual and considered trivial enough to be regarded as irrelevant, will apply to far larger numbers of patients than those for whom the intervention has any effect. This applies especially to population-based screening and to primary prevention. In both of these situations the intervention will be applied to very large numbers of patients compared with the few who are expected to derive any real benefit. Thus, for every death averted through a mammography screening program there will be hundreds of patients who undergo screening without it having any clinical outcome for them personally but who nevertheless need to travel to the clinic, wait around until they are seen, and then undergo the usually mild anxiety, discomfort, and inconvenience involved in the procedure. ${ }^{3}$ For every patient in which primary prevention with aspirin prevents a serious vascular event there will be over a thousand who have to take a tablet every day for a year without any benefit. ${ }^{5}$ Likewise, almost a thousand people need to be vaccinated against HPV for every death avoided. ${ }^{6}$

In order to attempt to assess how patients perceive the cost to themselves of what are regarded as routine medical interventions, I carried out an Internet-based survey in which participants were invited to put a financial cost on such activities as taking a tablet, receiving an injection, and being admitted to hospital. The survey sought to isolate the element of cost to the patient by asking people to imagine what they would charge if the procedure was of no benefit to them nor to medical science in general but was purely for commercial purposes. They were asked what they would charge to take a tablet daily with no side effects, with sedative effects, and with the effect of impaired sexual function. They were asked what they would charge to be given one injection, an injection on a regular basis and, if already in hospital, an injection which was painful and which produced stinging afterwards. They were asked what they would charge to be admitted to a general medical ward and a psychiatric ward. Invitations to participate in this survey were placed on a variety of websites, including an in-house journal for employees of a mental health trust, a website for users of mental health services, health-related Facebook groups, Twitter, and the researcher's own website. All these sites were UK-based and the invitation on the researcher's website requested that only potential users of the NHS complete it. Hence, it was expected that participants would consist largely of UK residents who would be a mixture of health service staff, service users, caregivers, and members of the public. The results of the survey are summarized in Table 1.

The intraquartile ranges demonstrate that people produced strikingly varied responses, which is important in itself. The median figures tended to be high and easily comparable with what the financial cost of the treatment might be for the health provider $-£ 5$ daily for a tablet with no side effects, $£ 200$ for a single injection, $£ 300$ per day for a medical admission, and $£ 400$ per day for a psychiatric admission. Of course these responses are based on a small number of self-selected subjects but there is no reason to suppose that they are especially unrepresentative. The implication is that incorporating subjective cost to the patient in costeffectiveness calculations may have a substantial effect and could easily lead to some interventions moving from being supported to unsupported.

Before leaving the survey, it is perhaps worth remarking on some other features. It was unsurprising that for most interventions the declared cost correlated with the income of the subject; that is, somebody who is better off will tend to charge more. The exception was for taking a tablet with no side effects, which was not correlated with income but which was weakly correlated with age. The cost of admission to hospital was correlated very highly with income, suggesting that loss of earnings or how much people valued their own time might be important. Interestingly, the cost to take medication with sexual side effects was highly correlated with income but not with age. The weak correlation of some other costs with age may be a result of the strong correlation between age and income which was present in this sample.

A related issue to consider is that in the context of a publicly funded health system such as the NHS, a useful evaluation of any intervention should consider its cost to 
Table I Survey results

\begin{tabular}{|c|c|c|c|}
\hline & $\begin{array}{l}\text { Median } \\
\text { (intraquartile range) }\end{array}$ & $\begin{array}{l}\text { Correlation with subject } \\
\text { age - tau } \\
(P \text {-value })\end{array}$ & $\begin{array}{l}\text { Correlation with subject } \\
\text { income - tau } \\
(P \text {-value })\end{array}$ \\
\hline $\begin{array}{l}\text { Daily cost to take a tablet } \\
\text { twice daily }\end{array}$ & $5(3-13)$ & $0.19(0.03)$ & 0.16 (NS) \\
\hline $\begin{array}{l}\text { Daily cost to take a tablet with } \\
\text { sedative side effects }\end{array}$ & $60(20-250)$ & 0.15 (NS) & $0.22(0.01)$ \\
\hline $\begin{array}{l}\text { Daily cost to take a tablet with } \\
\text { sexual side effects }\end{array}$ & $100(30-350)$ & 0.12 (NS) & $0.31(0.0005)$ \\
\hline Cost to have one injection & $200(60-400)$ & $0.20(0.02)$ & $0.26(0.004)$ \\
\hline $\begin{array}{l}\text { Cost for each of a series of weekly } \\
\text { injections involving attending a clinic }\end{array}$ & $100(40-100)$ & $0.21(0.019)$ & $0.27(0.002)$ \\
\hline $\begin{array}{l}\text { Daily cost to be admitted } \\
\text { to a general medical ward }\end{array}$ & $300(150-500)$ & 0.13 (NS) & $0.4 \mathrm{I}(<0.000 \mathrm{I})$ \\
\hline $\begin{array}{l}\text { Additional daily cost to have a } \\
\text { painful injection which stings } \\
\text { afterwards }\end{array}$ & $100(30-350)$ & 0.15 (NS) & $0.24(0.007)$ \\
\hline $\begin{array}{l}\text { Daily costs to be admitted to } \\
\text { a psychiatric ward }\end{array}$ & $400(250-700)$ & 0.088 (NS) & $0.42(<0.0001)$ \\
\hline
\end{tabular}

Notes: An internet-based survey was set up and responses were invited through a variety of sources including a newsletter for employees of a UK National Health Service trust, a service users' group, Facebook, and Twitter. A total of 104 responses were received of which 57 provided usable data. Participants were asked to declare how much they personally would charge in pounds sterling to undergo a particular medical intervention if it was devoid of benefit. Nonparametric correlation coefficients were calculated using Kendall's tau. The survey can be viewed online at: http://www.smd.qmul.ac.uk/statgen/dcurtis/survey.html.

Abbreviation: NS, not significant.

society as a whole, not just to the health provider. Thus, if an intervention impacts on the economic activity of the patient then it should not be possible simply to ignore this. Taking the example of mammography again, it might be that the economic cost to the patient and/or their employer could be minimized by setting up a mobile screening unit which went out to the patient's place of work and/or operated outside normal working hours. But then one could reduce the cost to the health service by providing a centralized service within working hours, meaning that the patient had to take time off work and to travel. This could be seen as artificially shifting the cost from the health service to the patient (whose costs are invisible) in order to end up with a screening program which would then be judged by conventional criteria as "cost-effective". Yet the overall costs to society for the centralized service might be the same or higher than for one which was more user-friendly. Using real world data, it has been proposed that practical barriers such as accessibility form an important reason for women to fail to attend for cervical screening. ${ }^{7}$ However, developing a service which attempted to address this problem would be likely to fail if conventional cost-effectiveness criteria were applied.

The suggestion that the subjective effects on a patient of undergoing a medical intervention should be routinely considered when weighing up its overall value may prove unwelcome. Since these effects may include pain, inconvenience, and financial costs, the overall effect could only be to tip the balance towards some interventions being considered not worthwhile. However, it is intellectually dishonest and morally indefensible to simply ignore the patient experience. I argue that standard cost-effectiveness evaluations do indeed ignore the patient experience and that it is time to review the appropriateness of the methodology.

\section{Acknowledgment}

Thanks to Ruth Curtis who provided the original inspiration for this work.

\section{Disclosure}

The author reports no conflicts of interest in this work.

\section{References}

1. Gotzsche PC, Hartling OJ, Nielsen M, Brodersen J, Jorgensen KJ. Breast screening: the facts - or maybe not. BMJ. 2009;338:B86.

2. Keen JD, Keen JE. What is the point: will screening mammography save my life? BMC Med Inform Decis Mak. 2009;9:18.

3. [No authors listed]. The trouble with screening. Lancet. Apr 11 2009; 373(9671):1223.

4. NICE. The Guidelines Manual. NICE; 2009.

5. Barnett H, Burrill P, Iheanacho I. Don't use aspirin for primary prevention of cardiovascular disease. BMJ. 2010;340:C1805. 
6. Kulasingam SL, Benard S, Barnabas RV, Largeron N, Myers ER. Adding a quadrivalent human papillomavirus vaccine to the UK cervical cancer screening programme: a cost-effectiveness analysis. Cost Eff Resour Alloc. 2008;6:4.
7. Waller J, Bartoszek M, Marlow L, Wardle J. Barriers to cervical cancer screening attendance in England: a population-based survey. $J$ Med Screen. 2009; 16:199-204.

\section{Publish your work in this journal}

Patient Preference and Adherence is an international, peer-reviewed, open access journal focusing on the growing importance of patient preference and adherence throughout the therapeutic continuum. Patient satisfaction, acceptability, quality of life, compliance, persistence and their role in developing new therapeutic modalities and compounds to optimize clinical outcomes for existing disease states are major areas of interest. This journal has been accepted for indexing on PubMed Central. The manuscript management system is completely online and includes a very quick and fair peer-review system. Visit http://www.dovepress.com/ testimonials.php to read real quotes from published authors.

Submit your manuscript here: http://www.dovepress.com/patient-preference-and-adherence-journal 